\title{
LIBERDADE NOS NÍVEIS PRIMITIVOS DA VIDA NA FILOSOFIA DE HANS JONAS
}

Liberty in the primitive levels of life in the philosophy of Hans Jonas

Bruno Henrique do Rosario Xavier.

Graduando em Filosofia - PUC Paraná.

Orientador: Dr. Anor Sganzerla - PUC Paraná

RESUMO: O tema central desse trabalho é a filosofia do organismo de Hans Jonas. Desse modo, o objetivo da presente pesquisa consiste em analisar a liberdade dialética nos organismos que sobrevivem graças à capacidade metabólica, segundo o sistema filosófico jonasiano. A metodologia utilizada foi a analítica sintética em que se percorreu as principais obras de Jonas sobre o tema, sobretudo, sua obra O princípio vida e de comentadores que auxiliaram no desenvolvimento do trabalho. Com o resultado da pesquisa constatamos que a liberdade já pode ser encontrada nos primeiros estágios de vida, mas de modo diferente daquele que se expressa nos seres humanos. Partindo do darwinismo, Jonas compreende que os estágios de liberdade vão se construindo de liberdade inferior à liberdade superior, camada sobre camada, em um sentido de evolução. É nesse sentido que Jonas afirma que o metabolismo é o elemento pelo qual o ser se distingue da mera materialidade sem objetivo, ao mesmo tempo que abre a possibilidade para a existência da subjetividade na matéria, colocando o ser orgânico na polarização entre o si mesmo e o mundo. Para manter seu ser, a vida precisa realizar seu fazer. Aqui é exposto o caráter precário da liberdade, pois na medida em que o orgânico escolhe a vida, ele precisa, necessariamente, o fazer, pois deixar de fazer significa morrer. É pela transcendência, pelo ter o mundo, que a vida orgânica afirma sua liberdade, que nesse contexto, tem predominância sobre a necessidade.

PALAVRAS-CHAVE: Liberdade dialética; Vida; Ontologia. 


\section{INTRODUÇÃO}

Esta pesquisa objetiva analisar os aspectos subjetivos do ser orgânico oriundos de sua soberana primazia no reino da matéria, a saber, do metabolismo. Sendo assim, o trabalho analisa o entendimento jonasiano da atividade metabolizante e quais os caracteres interiores que ela traz em si para a vida orgânica. Para tal fim utilizamos a leitura de textos filosóficos, em que percorremos as obras dos autores, com ênfase em O princípio vida, e em diversas obras de comentadores da área.

Para que a compreensão do tema ocorra de forma mais satisfatória possível, dividimos o presente trabalho em três seções principais: identidade e liberdade: uma análise do que aparece objetivamente do ser vivo a partir da leitura filosófica de Jonas do sistema metabólico, no qual analisaremos o fundamento da liberdade no sistema filosófico de Hans Jonas a partir do metabolismo; interioridade, teleologia, e transcendências do organismo primitivo: uma análise dos aspectos subjetivos da vida, em que analisaremos as consequências do pensamento anterior, isto é, a interioridade, e em que medida ela contribui para a compreensão da liberdade; e liberdade dialética, no qual compreenderemos como é possível falar de liberdade em um mundo marcado pela necessidade.

Se analisarmos, como Jonas fez, que herdamos da Modernidade uma ontologia da morte na qual todos os seres vivos foram submetidos aos princípios da res extensa, logo perceberemos que a reflexão sobre a ontologia da vida é de extrema importância devido às complicações que essa postura teórica trouxe para o campo ético. Ao remover da vida seu caractere de dignidade, o discurso do monismo materialista promoveu uma espécie de justificação de todo tratamento dos seres viventes (em especial da extra-humana) com um status ontológico como qualquer outro. Aliás, conceituar um termo como "vida" se tornara uma tarefa difícil em nosso tempo, e isso graças à definição que em geral adotamos de "matéria". Para o período moderno e o pensamento que se seguiu dele, a vida nada mais é do que um processo puramente mecânico de permutação material sem objetivos ou finalidades próprias. O problema, no entanto, é que essa concepção de vida não é suficiente para explicar a vida em sua totalidade uma vez que ela ignora os aspectos subjetivos da vida em nome de uma verdade objetiva. É por este motivo que precisamos alterar nossa concepção de vida e atribuir às demais espécies do planeta um processo que vai muito além

\footnotetext{
${ }^{1}$ O princípio vida tem duas principais edições: originalmente publicado em $1966 \mathrm{em}$ inglês sob o título de The Phenomenon of Life. Toward a Philosophical Biology, e posteriormente com o título de Organismus und Freibeit - Aufsätre zu einer philosophischen Biologie no idioma alemão (VIANA, 2014, p.393). Chamamos atenção para essas duas versões, pois ela se faz relevante para a presente pesquisa. No prefácio de 1972 desse mesmo livro, Jonas nos relata (2004, p.9) que o quarto capítulo não fora publicado na edição inglesa. Ora, fizemos tal distinção, pois a tradução na qual recorremos é a da versão alemã de 1973 e apenas ela traz em sua configuração o capítulo barmonia, equilibrio e devir conceito de sistema e sua aplicaśão ao terreno da vida, seção importante para o desenvolvimento da nossa pesquisa. Desse modo, devemos lembrar ao estudarmos o conceito de sistema na filosofia jonasiana a partir de O princípio vida estamos nos referindo à segunda edição da obra.
} 
da mecanicidade dos encadeamentos químicos que o constitui. Desse modo, estudaremos nesta pesquisa o conceito de vida orgânica para Jonas e suas implicações, tais como o conceito de identidade, e de liberdade aplicada ao organismo. Ora, de acordo com Jonas (2004, p.14), o estudo da liberdade é importante pois ela é o fio de Ariadne para interpretação daquilo que entendemos por vida. Assim, compreendemos que liberdade está intimamente conectada à vida, e a compreensão de uma nos ajuda na compreensão da outra. Nesse sentido, a pergunta que expressa a problemática que buscamos resolver é: como podemos diferenciar esses organismos da mera materialidade do mundo físico no sentido de podermos atribuir a uma classe de sistemas uma característica como a liberdade?

Antes de prosseguirmos com nossa pesquisa, precisamos ter claro em mente desde já o que Jonas entende por liberdade, ou nos espantaremos com a afirmação de que um ser apenas dotado com o metabolismo é já dotado de liberdade. Desse modo, quando, no decorrer do presente artigo, utilizamos o termo "vida", temos em mente um processo pelo qual um aglomerado de corpos materiais se distingue do reino da matéria pura através do metabolismo (JONAS, 2004, p.107), ou seja, a absorção de nutrientes do meio e a descarga de algum material para o mundo.

\section{UMA ANÁlISE DO QUE APARECE OBJETIVAMENTE DO SER VIVO A PARTIR DA LEITURA FILOSÓFICA DE JONAS DO SISTEMA METABÓLICO}

No prefácio da obra O princípio vida, Jonas afirma que “já o metabolismo, a camada básica de toda existência orgânica, permite que a liberdade seja reconhecida - ou que ele é efetivamente a primeira forma de liberdade" (JONAS, 2004, p.13). Isso implica que toda vida, isto é, um organismo possuidor de metabolismo, é um ser que carrega em si a forma mais primitiva de liberdade (que tem seu ápice no ser humano).

Mas o que exatamente Jonas tem em mente quando ele utiliza o termo "metabolismo" como definição do ser vivente? O termo alemão metabolismo é designado por Stoffweschsel e tem o significado de troca de matéria (COMÍN, 2005, p.44). Porém, esse conceito de metabolismo, quando tomado isoladamente não é o suficiente para definir o que é vida, e nos leva a dois problemas: a) se tomamos a definição de ser orgânico vivo pelo único critério do metabolismo, isto é, a capacidade de um agregado de matéria de absorver e ejetar substâncias fundamentais para seu funcionamento, podemos (e devemos) atribuir vida à máquina que absorve combustível e expele algum material que não lhe é mais necessário; b) além disso, o fato da vida orgânica estar com sua materialidade em constante transformação devido sua necessidade de nutrição, levaria a 
absurda afirmação de que em dois cortes temporais o organismo seria outro, não mantendo sua identidade como algo fixo. Os dois problemas, porém, não se encontram juntos, mas o segundo decorre da solução do primeiro.

Quando compreendemos troca de matéria com o meio, a analogia da máquina torna-se inevitável: afinal de contas, em que medida seria o ser orgânico diferente de um maquinário submetido à necessidade de absorver e expelir materiais?

A analogia da máquina, para Jonas (2004, p.98), não se sustenta como verdadeira, já que no caso do equipamento sem vida a identidade material é sempre a mesma, ou seja, o "metabolismo" (nesse caso, o "motor") não está envolvido na mudança de si mesmo no processo de troca de matéria com o mundo. Isso faz, segundo Jonas, a máquina se diferenciar do organismo, pois a primeira tem um sistema autoidêntico interno, já a segunda uma identidade material que está em constante mudança.

Além disso, devemos levar em conta também que a máquina não precisa de uma autocontinuidade, uma vez que podemos desligar o motor e voltar a ligá-lo quando nos aprouver, que a equipamento continuará funcionando. Quando desativamos o maquinário por um período de tempo, sua permanência material no espaço e tempo permite que ele seja idêntico em todos os momentos (salvo se ocorrer uma intervenção externa à máquina que a altere de alguma forma), nos permitindo assim definir sua identidade como a "lógica do vazio A=A" (JONAS, 2004, 104). Do ponto de vista do que é material, átomos, cadeiras, espelhos, etc., mantém sua identidade apenas pelo "estar aî" (JONAS, 2009, p.268). Assim, se olharmos um agregado de substâncias mais complexas, como uma bactéria através de um olhar analítico, veríamos que o organismo tem os mesmos traços gerais que as outras matérias (JONAS, 2012b, p.14). Isto quer dizer que somos levados a concluir erroneamente que um ser orgânico e uma gota de água adquirem o mesmo valor ontológico. Em outras palavras, a existência atual dos objetos não depende de nada além do que eles são agora, ou seja, da identidade material, e não precisam de autoafirmação a todo momento (JONAS, 2009, p.268).

Sistema aberto e sistema fechado ${ }^{2}$, eis os conceitos fundamentais para compreender como Jonas distingue o ser vivo, dotado de liberdade, da mera matéria morta. Enquanto o primeiro é marcado pela alteração do seu constituinte material, o segundo tem sua identidade definida por

\footnotetext{
2 Atribuir aos seres vivos a reflexão na qual eles são tomados como sistemas aparece primeiramente na Teoria Geral dos Sistemas de Ludwig von Bertalanffy, a qual Jonas menciona em seu O princípio vida, e a partir da qual funda sua ontologia do organismo. Devemos lembrar aqui que há diferenças fundamentais entre as duas teorias, como a mais crucial delas: "Diferentemente de Bertalanffy, Jonas insiste no fato de que o significado formal do organismo - que é sua característica ontológica particular - não pode ser completamente explanada pelas fórmulas matemáticaquantitativas de um de um sistema” (TIBALDEO, 2015, p.20, tradução nossa). Como já exposto na introdução, este importante conceito da filosofia do organismo jonasiana não está presente na edição The Phenomenon of Life, mas apenas na versão alemã de 1973.
} 
sua materialidade, por seu estar aí. Mas antes de nos aprofundarmos nessa distinção, precisamos antes de mais nada, compreender o que Jonas entende por sistema.

O objetivo de Jonas ao trabalhar o conceito de sistema em sua ontologia da vida é resolver o problema deixado pelo monismo materialista, a saber, a diferença entre material vivo e material morto. Em outros termos: como explicar a existência de uma unidade que se destaca da matéria que é em si mesma destituída de interesse como uma forma de ser que tem em si uma finalidade intrínseca? Jonas consegue encontrar essa diferenciação identificando um comportamento diferente do sistema do corpo vivo do que nos sistemas do restante da matéria.

O filósofo define um sistema da seguinte maneira: "Quais são as características gerais de um sistema? 'Sistema' significa a união de um sistema de coisas, uma combinação (um sistema é uma unidade de uma pluralidade)" (JONAS, 2012a, p.201, tradução nossa). Isso quer dizer, de acordo com Jonas (2004, p.76), que o conceito de conjunto determina o sentido de sistema e pressupõe uma pluralidade que esteve junta pela relação do conjunto, e que não pode existir de outra maneira que não seja por esta relação. É nesse sentido que Viana afirma que para Jonas “o organismo vivo é entendido como um sistema cujas partes são organizadas por um princípio elevado” (VIANA, 2014, p.394). Mas definição ainda não nos é suficiente para compreender como o conceito de sistema pode dar unidade ao conceito de vida. Para o entendermos melhor, de acordo com Jonas, precisamos analisar os critérios adotados para a definição dessa unidade. As regras precisam ser definidas uma vez que o princípio da semelhança pode ser usado de acordo com a vontade do indivíduo que está observando o sistema, já “os princípios do fundamento ou das condições, obriga que o pensamento assuma certos compromissos" (JONAS, 2004, p.76). Seguindo essa perspectiva Jonas argumenta que em uma poça de água as diversas gotas deixam de existir como uma pluralidade para se tornarem uma unidade (a própria poça de água). No entanto, a gota ainda é um sistema formado pelas moléculas, pois ela comporta um número finito de moléculas com a característica de gota. Isso implica que não pode existir um sistema infinito, mas também tampouco pode existir um sistema extremamente simples. Em suma, "o sistema é um meio termo entre o absolutamente uno e o infinitamente plural" (JONAS, 2004, p.77), o que permite nos dizer (pela finitude do sistema) que ainda existe um fora que distingue o sistema do restante do mundo ${ }^{3}$. No entanto, segundo Jonas (2004, p.76), para o ser, esta condição precisa significar que ele está conectado a si mesmo, ou seja, ele forma uma união de dependências, e quando alcança esta ligação, ele é um todo, e não apenas uma multiplicidade.

\footnotetext{
${ }^{3}$ Nesse sentido, o universo é um sistema na medida em que as forças que o constitui atuam em um campo finito de ordenação (JONAS, 2004, p.76). Nessa perspectiva, para Jonas (2012b, p.201), o sistema solar seria um sistema enquanto o Sol mantiver os corpos que o circundam unidos, de maneira que o movimento dos corpos dependa do movimento de outros.
} 
Isso implicaria que da mera existência desse sistema já resultaria na conservação e na permanência do equilíbrio dessa organização sistêmica.

A dinâmica do equilíbrio e desequilíbrio nos leva ao conceito de devir, pois "a ocasião para o novo está presente na mesma medida em que o desequilíbrio, e que o aproveitar desta ocasião, isto é, o efetivo devir de algo novo, nasce unicamente do dinamismo do desequilíbrio" (JONAS, 2004, p.79). É justamente a oscilação permanente e irregular que permite que o sistema funcione.

O dinamismo do desequilíbrio impele o conjunto dos corpos ao movimento. Mas que é um movimento na teoria dos sistemas jonasiana? Ora, movimento é o retornar periodicamente de estados idênticos. Jonas afirma que o período é o tempo próprio do sistema. Segue-se disso que só pode existir história enquanto este processo de equilíbrio e desequilíbrio estiver ocorrendo. Ou seja, quando o sistema está se construindo ou se desfazendo, ele permanece em movimento, mas enquanto o sistema é sempre constante, não é dotado de história, de modo que "os aspectos da harmonia e da historicidade se excluem mutuamente" (JONAS, 2004, p.79). Um conceito de sistema sem historicidade só poderia ser aplicado em um conjunto perfeitamente harmônico, o que pode ser apenas uma aparência do referencial humano ${ }^{4}$, ou seja, como se alguns movimentos fossem imperceptíveis, mas, no entanto, existentes, quebrando assim a harmonia perfeita do sistema. No entanto, nesse caso devemos buscar um ponto mais abaixo do sistema nãoharmônico em que nos permita apontá-lo como uma unidade apesar de sua movimentação, de modificação inerente a si. Ora, do constante equilíbrio e desequilíbrio que garantem a unidade do sistema e sua permanência como idêntico a si mesmo na multiplicidade espacial, podemos afirmar que voltada ao campo dos seres vivos, a dinâmica incerta tem uma singularidade, pois para a vida o constante decaimento do sistema representa a dimensão finita de si mesma, ou seja, a própria morte (JONAS, 2004, p.82).

É, portanto, no decaimento que Jonas identifica o ponto que permite notar que mesmo através do movimento há uma unidade no sistema orgânico que mantém o ser vivo como uma identidade diferençável de outros seres do mundo. É por isso que ao falar do sistema aberto do organismo Jonas afirma que o manter de um sistema orgânico é:

Um meio termo entre o devir e o perecer, entre o ser e o não ser. Um meiotermo, porém, não no sentido indiferente de ele simplesmente se encontrar entre duas coisas, e sim no sentido crítico de manter o equilíbrio, de que pelo fato de existir ele detém a queda mas que no próprio exercício de sua função

\footnotetext{
4 Ainda tomando o exemplo do sistema solar, podemos compreendê-lo como um sistema com historicidade na medida mesma medida em que os corpos celestes descrevem uma espiral em direção ao sol, deixando assim o sistema sempre em decaimento, ao contrário do sistema harmônico no qual os planetas descreveriam trajetos perfeitos e inconstantes ao redor da estrela solar.
} 
repetidora, ele não pode deixar de ir caindo, já que só pela queda pode conseguir os meios termos para detê-la, tendo a cada movimento representar o 'meio' em um ponto mais rio abaixo (JONAS, 2004, p.82).

Dentro dessa perspectiva, cada um dos momentos do ser vivo acrescenta-lhe algo sempre novo, o que não acontece no fora do âmbito dos seres metabólicos, pois eles são sempre definidos por seus elementos simultâneos fazendo que seus estados sejam a expressão contínua de uma multiplicidade espacial que é definida de uma vez por todas (JONAS, 2004, p.81). É nesse sentido que Jonas afirma que o conceito de equilíbrio é como um correspondente moderno do conceito de harmonia da antiguidade. Ou seja, o sistema, justamente pelo fato de existir, detém em si sua própria queda. Por esse motivo no campo da vida esse aspecto do sistema tem um caráter particularmente adequado, uma vez que o vivente é sempre obrigado a sucumbir, e é a cada momento empurrado para a morte (JONAS, 2004, p.82).

A vida, isto é, um sistema aberto:

Diferentemente do sistema fechado da mecânica clássica, [...] não é expressão de um equilíbrio existente, mas sim o constante estabelecimento e restabelecimento do equilíbrio. O fato de o restabelecimento ser necessário está ligado à própria abertura, por exemplo, no caso do metabolismo, à perturbação do equilíbrio pela sua carência que ocorre naturalmente [...]. O tipo de periodicidade que ocorre aqui já não é o de um ciclo de estados equivalentes, mas sim o oscilar entre o ser e o não-ser, um equilíbrio móvel de devir e perecer, e neste sentido um acontecer autêntico (JONAS, 2004, p.85, grifo nosso).

Chegamos aqui aos fundamentos da teoria jonasiana que nos permitirá encontrar traços no organismo primitivo, pois é a partir dessa oscilação entre ser e não-ser que será possível estabelecer a intencionalidade (portanto, liberdade) orgânica. Ora, é devido ao estado dinâmico da metabolização do sistema que o organismo altera substancialmente a si mesmo. Para que o sistema funcione, seu desequilíbrio (falta de nutrientes) precisa rapidamente ser "restaurado" ao estado de equilíbrio "original”, o que leva o ser orgânico a buscar no mundo a matéria necessária para sua sobrevivência.

Esse fato de mutação de si do ser vivo exige que a identidade não possa ser mais encontrada na matéria uma vez que ela é mera transitoriedade e está sujeita às mudanças constantes. O processo pelo qual organismo tem sua identidade não depositada na materialidade é chamado por Jonas de "revolução ontológica" (JONAS, 2004, p.104). Nessa perspectiva, Moura 2015, p.582) afirma que a identidade de si mesmo é um caráter ontológico que se mantém operante ante a modificação da matéria, fazendo a liberdade manifesta surgir como forma independente do reino material. Percebemos desse modo como Jonas resolve o problema da identidade, visto que a matéria transicional é sempre o pano de fundo no qual o organismo 
constitui a si mesmo. Em outras palavras, é a unidade do sistema que permite identificar um organismo como um "si mesmo". Do conceito de "si mesmo" da existência orgânica podemos identificar que a identidade da vida nos aparece em dois horizontes: "um interno - o tempo como a fase seguinte de sua existência para a qual se dirige; e um externo - o espaço - como lugar do outro, do mundo, igualmente presente e da qual depende a continuidade de seu ser" (MOURA, 2015, p.583, grifo nosso). É a identidade interna do organismo abre a dimensão da interioridade, e é aí que se encontra a intencionalidade orgânica.

\section{INTERIORIDADE, TELEOLOGIA, E TRANSCENDÊNCIA DO ORGANISMO PRIMITIVO}

Como observamos na seção anterior, Jonas aponta para a existência da interioridade orgânica, que é uma expressão individual do isolamento do organismo em relação ao mundo, e tem sua manifestação mais acentuada nos processos de transcendências temporal e espacial. Essa identidade do organismo, tida como a identidade ontológica, tem seu ápice na dimensão da interioridade. Assim sendo, todo organismo dotado de metabolismo tem interioridade ou subjetividade, que inclui os encontros que ocorrem dentro da mesmidade sentida, ainda que essa sensação seja fraca (JONAS, 2004, p.109). Por este motivo o estudo da teoria sistêmica aplicada ao organismo é de vital importância para compreendermos o conceito de vida nas considerações de Jonas, pois apesar de ser objetivamente observada, das consequências dela o filósofo alemão retira os aspectos sentidos do próprio corpo vivo e assim chega ao conceito de subjetividade.

Utilizamos acima o termo "subjetividade", porém, há um ponto importante a ser lembrado a essa altura: de acordo com Lopes (2010, p.59-60), quando Jonas utiliza a palavra "subjetividade", ele não se refere à uma subjetividade mental, mas em uma espécie de gradação de subjetivos configurada de uma maneira que se uma subjetividade mental tiver que descer alguns níveis na gradação, chegará um momento em que não será possível encontrar um sujeito. Isso não quer dizer, no entanto, que não exista intencionalidade ou interioridade nessa subjetividade, ainda que não esteja mais dentro do campo mental. A esse aspecto gradativo da subjetividade, Jonas dá o nome de transcendência imanente, que é uma espécie de "espírito invisível" presente em todos seres vivos, e apesar de ser "invisível", é o que mais se vê, pois corresponde ao "eu” da liberdade (OLIVEIRA, 2015, p.45).

Para esclarecer ainda mais esse termo, se faz necessário diferenciarmos dois termos aqui: ipseidade e psique. De acordo com Jonas (2006, p.139), enquanto a psique está presente no organismo desde sua camada mais básica até as existências elevadas, a ipseidade é encontrada em 
seres ainda não conscientes, mas que estão mais "evoluídos" no processo de gradação da subjetiva. Assim sendo, nos dizeres de Lopes, a psique para Jonas "encontra expressão em qualquer forma de impulso como tal, e a outra [ipseidade] se refere ela sim à esfera propriamente da individualidade, onde então já se pode falar de um sujeito” (LOPES, 2010, p.60). É papel da psique e não da ipseidade carregar a interioridade orgânica. Nesse contexto, "o que Jonas compreende como 'subjetividade em estado latente' poderia ser traduzido em 'subjetividade ainda exteriorizada', isto é, uma estrutura finalista ainda não consciente, como acontecerá no espírito humano" (VIANA, 2015, p.572).

Para não pensarmos que o termo subjetividade tem uma relação direta com o que comumente entendemos por ter uma subjetividade, precisamos levar em conta que a esfera subjetiva em Jonas está além da existência cerebral ou neuronal e vai dos mais elevados graus da vida até os primitivos estágios dos organismos através do que Jonas chama de "salto qualitativo" (JONAS, 2010, p.32). Mais ainda, Jonas (2010, p.19) chega a dizer que a subjetividade é um fato empírico (o aparecimento da vida a partir de arranjos químicos-morfológicos da matéria), porém não o é o horizonte interno que se abre a partir daí.

Em suma, o ser vivente parte da troca química de matéria com seu entorno e com isso define os limites espaciais da sua identidade, mas ao fazê-lo, o organismo abre em si a camada subjetiva da vida. Nesse sentido, a identidade orgânica junto com o metabolismo é responsável por trazer à luz a dimensão subjetiva do ser vivente.

\subsection{INTERIORIDADE ORGÂNICA}

Partindo do conceito de interioridade orgânica, percebemos que "por estar aberta para fora, a identidade interior é o polo subjetivo da comunicação com o mundo" (MOURA, 2015, p.579). A abertura do organismo para o mundo, isto é, sua transcendência para buscar fora de si a matéria necessária para a autoconservação, é ela toda a iniciação da identidade ontológica, que é, por sua vez, o início do subjetivo no ser orgânico, isto é, da interioridade teleológica. Em suma, a independência da forma em relação à matéria (primeira expressão da liberdade orgânica), já forma a possibilidade de interioridade, e a interioridade se efetiva no real ato de transcender no espaço e no tempo. Mas o que é essa interioridade? Vejamos a definição de Jonas:

Quer chamemos esta interioridade de sensação, sensibilidade e resposta à estímulos, busca ou tendência - em certo grau (mesmo infinitesimal) de percepção sensitiva ela obriga o interesse absoluto do organismo em sua própria existência e sua preservação - isto é, ela é "egocêntrica" -, ao mesmo tempo que supera o fosso qualitativo em relação ao resto das coisas através de 
modos de relação eletiva, que com sua peculiaridade e urgência substituem para o organismo o lugar da integração geral das coisas materiais em sua vizinhança física (JONAS, 2004, p.109).

Isso quer dizer que a existência orgânica em sua dimensão de interioridade, através da atividade metabólica, expressa seu interesse pela vida a partir da intencionalidade. Ou, como nos mostra Moura 2015, p.579), não pode existir organismo sem interioridade, nem interioridade sem teleologia, de modo que interioridade e teleologia estão intimamente conectadas. Para Jonas (2004, p.109) o horizonte aberto do organismo significa afetabilidade e espontaneidade, de modo que ao se expor ao exterior, o organismo chega ao exterior, pois é assim, isto é, sendo sensitiva, que a vida é ativa. Segundo Weber (2002, p.189), a própria afetabilidade, na filosofia do organismo de Jonas já é um eu rudimentar, pois o que é sentido é sempre sentido a partir de um eu.

Ora, podemos ver que é justamente nesse ponto que Jonas fundamentará intencionalidade orgânica, isto é, na abertura com o mundo que inclui uma intencionalidade em preservar a vida pelo metabolismo, que é, essencialmente, uma abertura para a exterioridade. E nesse ponto relembramos as investigações de Jonas a respeito da atividade metabólica, pois como nos lembra Lindberg (2005, p.8), é o metabolismo que é o responsável pela divisão entre interioridade e exterioridade, de tal modo que a atividade metabólica produz interioridade e exterioridade de maneira inter-relacionadas, não existindo, portanto, primeiro um e depois o outro. Podemos comprovar esse ponto de vista se lermos ao texto de Jonas e percebermos que na metabolização, ao ser afetado por algum estranho, o ser que é afetado sente a si próprio de maneira tal que sua identidade (mesmidade) é definida pelo que vem de fora. Isso quer dizer que é pela relação do mundo com o organismo que a vida sente a si mesma, fortalecendo assim o aspecto da interioridade, ou, "sua mesmidade e como que iluminada pela outridade do fora" (JONAS, 2004, p.109).

Podemos dizer que há uma dinâmica de passividade e atividade que pode ser percebida em dois níveis (aqui apenas didaticamente separados): do metabolismo enquanto troca de energia com o meio, e da interioridade enquanto constituição do "si mesmo" e efetivação da liberdade no organismo. Esse é o aspecto passivo do organismo, que é sempre afetado pelo que chega do exterior (DUARTE, 2015a, p.55). Nesse ponto já é possível destacar o caráter de liberdade necessitada, na medida em que o organismo depende do que afeta e da afetabilidade que atua sobre ele para afirmar a mesmidade no mundo. É a partir daqui que Jonas pode buscar no ser vivo sua subjetividade, no sentido de encontrar um "eu" que faz uma oposição ao "mundo", uma mesmidade que é oposta a tudo que é a outridade, ainda que essa mensagem seja fraca e obscura (JONAS, 2004, p.109). 
A interioridade, só pode ser afirmada a partir da identidade do organismo, isto é, da sua separação com o mundo no sentido de diferenciação de sistemas, pois enquanto a interioridade é experimentada pelo organismo, a identidade é que traça os limites entre a mesmidade e a outridade. A interioridade é, a experiência interna da identidade em um sistema monista integral. Dentro dessa perspectiva, identidade e interioridade se complementam, e uma não pode existir sem a outra, de modo que formam uma unidade no organismo vivo.

Dito isso, precisamos nos atentar para o fato de que esse reconhecimento do organismo como um ser dotado de identidade e interioridade só o é através do processo da atividade metabólica, que tem sua expressão nas transcendências da vida, na transcendência temporal e espacial, que implicam em uma intencionalidade, teleologia, ou ainda, em uma liberdade do organismo. Se autoafirmar-se na teoria Jonasiana é viver como desejo (JONAS, 2004, p.14), então podemos identificar nas transcendências a intencionalidade orgânica e o início do ato de liberdade como um meio de conservação.

Desse modo chegamos ao polo subjetivo da vida que aparece graças ao autoisolamento do orgânico, e vemos assim que "deparamo-nos aqui com a estrutura dialética que perpassa todos os caracteres ontológicos da vida, fazendo-a aparecer de todos os lados como um paradoxo da existência material (JONAS, 2004, p.110). Ora, a vida sente o estranho pelo caráter passivo da transcendência, e é através dela que ela confirma sua interioridade. Se acima utilizamos o termo liberdade foi para mostrar que a vida não é marcada por forças puramente cegas e mecânicas. Podemos ver que a interioridade orgânica aparece de dois modos: o passivo, marcado pelo intruso que afeta o ser orgânico; e o ativo, marcado pela liberdade necessitada do organismo que busca autoafirmar-se através da autotranscedência temporal e espacial.

\subsection{ASPECTOS TELEOLÓGICOS ${ }^{5}$ DO ORGANISMO PRIMITIVO E SUA RELAÇÃO COM A LIBERDADE.}

Uma vez que vimos que a interioridade implica em uma intencionalidade, estudaremos no decorrer dessa subseção a teleologia orgânica e sua manifestação no ser metabólico. Mas o que é teleologia para Jonas? Como pode a matéria, algo em si mesmo indiferente em teleologia, ter em suas formações uma intencionalidade?

\footnotetext{
${ }^{5}$ Teleologia e intencionalidade podem ser tomados como sinônimos. No entanto, segundo Lindberg (2005, p.11), quando Jonas adota o termo teleologia ao invés de intencionalidade, ele tem em mente três fatores: intencionalidade é um termo que pode ser incluído dentro do termo teleologia; o termo teleologia 'prepara o terreno' para o campo ético, ao qual Jonas leva sua filosofia do organismo; e o terceiro motivo que é incluído pela comentadora, seria que teleologia permite um diálogo com o século XIX, que é a motivação mais ou menos secreta de todas fenomenologias da vida. De qualquer modo, o primeiro e o segundo fator são importantes para nosso trabalho, pois eles nos mostram como intencionalidade e teleologia podem ser utilizadas como sinônimo
} 
Segundo Duarte (2015a, p.54), Jonas entende teleologia de duas formas: teleologia como sendo imanente ao organismo, ou como teleologia transcendente, que precisa de uma entidade exterior no processo com seu propósito exterior a ser executado. Jonas adota para sua filosofia do organismo a teleologia imanente, a qual é expressa pela intencionalidade da vida orgânica de permanecer na existência (DUARTE, 2015a, p.54).

Para Jonas (2004 p.25), intencionalidade, isto é, a inclinação para um objetivo, ocorre nos seres vivos de uma maneira manifestamente subjetiva, mas que também ocorre de modo objetivo e causal pelo processo metabólico. Teleologia é, para Jonas, um movimento do ser em relação à sua matéria (LINDBERG, 2005, p.11), expressando assim sua conexão com a liberdade como sendo independência da forma em relação ao material.

Contudo esse movimento do metabolismo de "causalidade é teleológico e não unicamente mecânico" (WEBER, 2002, p.188, tradução nossa). Percebemos assim que não seria possível sequer reduzir o organismo aos processos químicos nesse contexto, pois tal redução pressuporia o desconhecimento da natureza teleológica da causalidade interna do ser orgânico. Nesse sentido, a teleologia para Jonas pode ser concebida de modo que o:

Universo que acolhe finalidades desde o seu núcleo mais ínfimo, é a própria concepção de um finalismo no interior do próprio vir-a-ser da natureza; uma espécie de finalismo que [...] [se insere] na perspectiva de um mundo em processo (LOPES, 2010, p.61).

Isto quer dizer que o mundo tem em si a capacidade para a teleologia da vida. Nas palavras de Jonas (2004, p.26), as causas finais precisam ser admitidas dentro do conceito causalidade universal. Essa maneira de Jonas conceber a teleologia como algo possível dentro do próprio reino material é chamada de "neo-finalismo" (LOPES, 2010, p.60). O ser orgânico é, portanto, um ser teleológico, pois suporta em sua estrutura básica a capacidade para viver segundo objetivos.

O organismo ao metabolizar realiza um ato exclusivamente seu, que impulsionado pela necessidade vital, realiza a liberdade no encontro com o mundo e com o mais-além. Em suma, podemos dizer que para Jonas (2004, p.108), os dois modos de transcendência orgânica ocorrem a partir da separação entre o si mesmo e o mundo pelo processo metabólico. A afirmação anterior é de grande importância para a nossa pesquisa, pois é neste campo de transcendência pelo metabolismo que encontraremos o ato de liberdade e de necessidade da vida orgânica.

Essa transcendência infinita, esse voltar para-si-mesmo, é o sentido fundamental de sua atividade teleológica. A explicação de Jonas do "ter-omundo" mostra como teleologia [...] atravessa a distância através de uma 
abertura e segue para si mesma novamente. Teleologia é, para Jonas, a lei da experiência que revela o espaço-tempo concreto" (LINDBERG, 2005, p.12, tradução nossa).

A citação acima mostra o caráter de continuidade da transcendência, de modo que o organismo se vê sempre obrigado a realizá-la, isto é, de transcender pelo tempo e pelo espaço biológico. Ora, Jonas afirma que na troca de matéria com o meio, "a forma viva tem que dispor de matéria, e ela encontra fora de si, no 'mundo' estranho” (JONAS, 2004, p.108). Segundo o pensamento jonasiano, o interesse do "si mesmo" de adquirir matéria do mundo é um encontro com a realidade externa, o que faz o organismo abrir seu ser para a transcendência. O que Jonas entende por transcendência? Ora, "quando falamos de transcendência da vida, queremos dizer que ela mantém um horizonte, ou horizontes, além de sua identidade puntiforme" (JONAS, 2004, p.110). Esse processo de transcender a vida é uma face do processo metabólico. Mas por que atividade metabólica e com ela a transcendência do organismo ocorrem? É pela necessidade de buscar nutrientes para manter a subsistência que a vida precisa abrir-se sempre para fora no espaço, e para um mais-além no tempo.

O mundo é para o ser orgânico um "um horizonte aberto pelo mero caráter transcendente da carência" (JONAS, 2004, p.108), e a revolução ontológica tem como finalidade ter-o-mundo para a sobrevivência do organismo. O fundamento da vida está no ato de autotranscender, que nos estágios mais avançados do ser vivo, também se desenvolve de modo mais complexo (JONAS, 2004, p.109). Esse modo de buscar no mundo o material para sua existência, ou ainda, o direcionamento externo do organismo em relação ao co-presente, é chamado de espaço biológico, ou seja, quando o organismo encontra em seu externo algo que é potencialmente seu (DUARTE, 2015a, p.56).

A forma de transcendência encontrada até aqui está dentro do horizonte espacial, isto é, ela ocorre no processo em que o si-mesmo, ou seja, a identidade do organismo, que através do autotranscender quer ter-o-mundo no espaço simultâneo. No entanto, como nos mostra Jonas (2004, p.110), também há o horizonte temporal, em que o autointeresse da vida pela sua preservação está marcado por um interesse projetado para o futuro próximo. Ora, enquanto a transcendência no horizonte espacial implica em uma transcendência sempre para fora, no temporal, a transcendência ocorre interiormente. Mas o que é, exatamente, a transcendência em seu aspecto temporal? Ela é "o estar-iminente daquele futuro mais próximo, para onde em cada momento a continuidade orgânica está a caminho para satisfazer a carência precisamente deste momento" (JONAS, 2004, p.110). No autoisolar-se do mundo, o organismo não o faz de maneira completa, caso contrário, ele perecerá. Mas é por meio desse não-completo isolamento 
que o ser orgânico encontra sua interioridade. Isto é, essa dupla face da transcendência ocorre para dentro (dimensão temporal), e para fora (dimensão espacial):

\begin{abstract}
Assim como seu aqui estende-se para o ali, assim também seu agora estende-se para o logo-mais, e a vida se encontra ao mesmo tempo nos dois horizontes "além" de sua própria imediatez. Ou mesmo: ela só olha para fora porque através da necessidade de sua liberdade olha para a frente, de modo que a presença no espaço por assim dizer se clareia ao ser iluminada pelo logo-mais no tempo, ambas passando para a realização e também apara a decepção (JONAS, 2004, p.110).
\end{abstract}

Isto é, o organismo está projetando seu interesse na vida também para um futuro próximo, um futuro pelo qual ele está metabolizando a matéria em seu entorno para sobreviver aos diversos riscos que a vida apresenta consigo. Jonas (2004, p.110) também argumenta que é pela relação transitória entre forma e matéria que esse interesse da vida por se manter viva se manifesta, isto é, a fase interior do organismo que se estende até a seguinte, é a que constitui o tempo biológico, um correspondente ao tempo do sistema no mundo orgânico do qual já falamos. A abertura do organismo para o mundo, ou para o não-ele-mesmo, corresponde ao material necessário para a constituição biológica do ser orgânico.

É a transcendência do ser orgânico que implica tanto seu caráter de liberdade, quanto de necessidade. Vimos que esse processo ao qual está a vida obrigada a se submeter para manter sua existência não se limita somente ao ser necessário do organismo, como também atinge sua esfera de liberdade. Mas em que sentido é possível de falar em liberdade em um mundo marcado pela necessidade?

Antes de respondermos à indagação anterior, buscaremos conceituar necessidade no pensamento de Jonas, para que possamos compreender melhor a liberdade no organismo primitivo. O que Jonas entende por necessidade? A necessidade seria a cadeia causal do mundo, o jogo de forças da matéria que no campo da vida determina certas regularidades, a saber, a obrigação da nutrição e a obrigação de evitar a morte (WOLIN, 2003, p.172). Se para a tradição moderna o metabolismo era apenas um jogo de reações químicas que impulsionava a vida sempre para frente, mas sem nunca impor finalidade a ela, para Jonas esse dever do organismo representa sua própria manifestação de liberdade. O que há no orgânico é uma coexistência entre liberdade e necessidade, o que garantiria a unidade psicofísica do organismo. Não se trata, portanto, de entidades separadas e incomunicáveis em que necessariamente, excluir-se-iam mutualmente, mas da manifestação do orgânico que mostra seus dois modos de existir, um pelo poder, e outro pelo dever. 
Nesse sentido, ao afirmarmos que o organismo é dotado de liberdade, queremos dizer que ao realizar a fotossíntese, por exemplo, uma planta está exercendo sua liberdade, do mesmo modo que esta é obrigada a fazer, pois se não o fizer irá perecer. Em outras palavras, necessidade e liberdade existem simultaneamente. À relação entre o ser livre e necessário, Jonas dá o nome de "liberdade dialética" (JONAS, 2004, p.107). Desse modo, o orgânico tem o poder de fazer, mas não o tem para omitir, ou seja, o poder significa dever na medida que o importante para o organismo é manter seu ser. Porém, devemos lembrar aqui que para Jonas (2009, p.267), o ser do organismo é seu próprio fazer, e, posto que a condição desse fazer não depende apenas do organismo mesmo, mas do favorecimento de um ambiente que pode ser outorgado ou recusado, a ameaça de deixar de existir habita com a existência orgânica desde o seu surgimento. Se estabelece aqui a indissolúvel relação entre a vida e morte, visto que "a vida é mortal, não apesar de ser vida, mas precisamente porque é vida segundo sua mais primitiva constituição" (JONAS, 2004, p.15, grifo nosso), o que torna a vida e a morte indesatáveis uma da outra, tal como a liberdade e a necessidade, o espírito e a matéria. A vida não existe, dentro desta perspectiva, sem a morte, pois o orgânico só mantém seu ser devido sua negação à morte, porém, estamos de acordo com Viana (2015, p.571) quando o comentador afirma que a morte é uma negação radical do ser, e mesmo assim a vida se encontra entre o ser e o não-ser por ela ser instável e estar oscilando entre a existência e não-existência. É por isso que o ser orgânico precisa se afirmar a todo momento seja no tempo ou no espaço, para manter sempre distante o seu oposto.

Ser, isto é, existir enquanto organismo metabolizante, é viver em risco, de maneira que a liberdade se encontra sempre como uma oposição à vida a tal ponto que a vida precisa manter-se continuamente com seu esforço e suas aberturas, tanto no espaço, quanto no tempo, para manter-se. É exatamente por isso que devemos lembrar a afirmação de Jonas no prefácio do O princípio vida, na qual o autor afirma que "ser, em vez de um estado, passou a ser uma possiblidade imposta, que continuamente precisa ser conquistada ao seu contrário sempre presente, o não-ser, que inevitavelmente terminará por devorá-lo” (JONAS, 2004, p.15, grifo nosso). Liberdade e necessidade, nesse sentido, estão correlacionadas à vida e à morte.

\section{CONSIDERAÇÕES FINAIS.}

Apresentamos como o metabolismo, que é elemento fundamental da vida, nos permite encontrar a liberdade orgânica. Dentro dessa perspectiva, buscamos analisar o conceito de metabolismo e a identidade do sistema aberto, para que então pudéssemos estudar a interioridade 
orgânica. Foi a partir do conceito de sistema aberto que analisamos a diferença entre o organismo vivo e organismo não vivo dentro da filosofia jonasiana.

Enquanto identidade orgânica, o ser vivo abre na troca de matéria com o ambiente a dimensão interioridade. A vida passa a ser marcada pela relação entre o ser e o mundo, o "si mesmo e o "eu" que é portador daquela intencionalidade.

Aqui encontramos o ponto de união de liberdade e necessidade pela transcendência. Mas vimos também que existem diferentes níveis de liberdades no pensamento filosófico jonasiano, sendo a liberdade primitiva o modo germinal de ser da liberdade presente nos seres humanos e nos animais que se dividem em outras instâncias e ajudam a formar a totalidade dos seres mais complexos. A liberdade vai crescendo então de forma ascendente, dos organismos menos evoluídos para os mais evoluídos.

Uma vez que o pensamento filosófico de Jonas costuma se encontrar tão distante das nossas reflexões comuns, isto é, de atribuir aos organismos primitivos a liberdade, toda a dignidade é devolvida ao reino extra-humano, o que nos permite assim levar em consideração não apenas o pensamento ético antropocêntrico, como também uma nova ética biocêntrica.

\section{REFERÊNCIAS BIBLIOGRÁFICAS}

COMÍN, Illana Giner. Introducción a la edición española. In HANS, Jonas. Poder o impotência de la subjetividad. Tradução de Illana Giner Comin. Coleção Pensamento Contemporâneo. Barcelona/Buenos Aires/México: Paidós, 2005, p.13-70.

DUARTE, Michelle Bobsin; FILHO, Edgard José Jorge. Hans Jonas: Da crítica à ontologia da morte ao fundamento da ontologia da vida. 2015. 88 f. Dissertação (Mestrado) - Pontifícia Universidade Católica do Rio de Janeiro, Rio de Janeiro, 2013. Disponível em: $<$ http://www.maxwell.vrac.puc-rio.br/25625/25625.PDF>. Acesso em: 28 mar. 2015a

JONAS, Hans. Lecture 1. In: verlag, 2012a. Disponível em: < Major Systems of Philosophy. Freiburg: Rombach http://www.lettere.uniroma1.it/sites/default/files/649/jonas_dottorandi.pdf> Acesso em: 28 mar. 2015a.

Matéria, espírito e criação. 1. ed. Petrópolis: Vozes, 2010

2004.

O princípio vida: fundamentos para uma biologia filosófica. 2. ed. Petrópolis: Vozes,

O fardo e a benção da imortalidade. Trad. Wendell Evangelista Soares Lopes. Princípios. Natal, v.16 n. 25 jan-jun, p. 265-281, 2009.

2012b.

Pensar sobre Dios y otros ensayos. Trad. Ângela Ackermann. 3 ed. Barcelona: Heder, 
O princípio responsabilidade: ensaio de uma ética para a civilização tecnológica. Rio

de Janeiro: Contraponto, 2006

LINDBERG, Susanna. Hans Jona's theory of Life in the face of Responsibility. In: LEMBECK, Karl-Heinz; MERTENS, Karl; ORTH, Ernst Wolfgang (ed.) Phänomenologische

Forschungen. [S.1], 2005. Disponível em:

<http://www.helsinki.fi/teoretiskfilosofi/personal/Lindberg/Lindberg_HansJonas.pdf>.

Acesso em: 28 mar. 2016.

LOPES, Wendell. A renovação da teleologia em Hans Jonas: da biologia filosófica aos fundamentos da ética. Princípios. Natal, v. 17, n. 28, p. 47-70, 2010. Disponível em $<$ https://dialnet.unirioja.es/servlet/articulo?codigo=3582064>. Acesso em 23 mar. 2016.

MOURA, Sarah. Fundamentos da ética do futuro de Hans Jonas: os princípios vida e responsabilidade. In: CARAVALHO, Marcelo, et al. Filosofia Política Contemporânea: Coleção XVI Encontro ANPOF. São Paulo: ANPOF, 2015.

OLIVEIRA, Jelson. Responsabilidade. In: MORETTO Geovani, OLIVEIRA, Jelson, SGANZERLA, Anor. Vida, técnica e responsabilidade. São Paulo: Paulus; 2015. p. 15-74

TIBALDEO, Roberto Franzini. The meaning of life. Can Hans Jonas' philosophical biology effectively act against reductionism in the contemporary life sciences?. Humaniora.

Czasopismo Internetowe, n. 01, p.13-24, 2015. Disponível em:

$<$ http://humaniora.amu.edu.pl/sites/default/files/humaniora/Humaniora\%20 $\mathrm{nr} \% 209 / \mathrm{H}$ um_1_15_Tibaldeo.pdf>. Acesso em: 25 jan. 2015

VIANA, Wellistony Carvalho. O monismo integral de Hans Jonas contra o fisicalismo. In: Aurora, v. 26, n. 38, jan-jun p. 391-403, 2014.

. A filosofia da natureza de Hegel e Jonas. In: CARAVALHO, Marcelo, et al. Filosofia Política Contemporânea: Coleção XVI Encontro ANPOF. São Paulo: ANPOF, 2015.

WEBER, Andreas. Feeling the signs: The origins of meaning in the biological philosophy of Susanne K. Langer and Hans Jonas. Sign Systems Studies, v. 30 n.01, p. 183-200, 2002. Disponível em: <http://philpapers.org/rec/WEBFTS-2> Acesso em: 25 jan. 2016.

WOLIN, Richard. Hans lonas: el filósofo de la vida. In Los hijos de Heidegger. Hannah Arendt, Karl Lwith, Hans Jonas y Herbert Marcuse. Trad. María Candor. Madrid: Cátedra, 2003. 